\title{
METAPHORICAL MEANING MAKING: DISCOURSE, LANGUAGE, AND CULTURE
}

\section{INTRODUCTION: MEANING MAKING IN LANGUAGE AND CULTURE}

Both culture and language are about making meaning. This view of culture comes closest to that proposed by Geertz (1973), who wrote: "Man is an animal suspended in webs of significance he himself has spun. I take culture to be those webs, and the analysis of it to be therefore not an experimental science in search of law but an interpretative one in search of meaning." (Geertz, 1973: 5). In this spirit, I suggest that we approach both culture and language as "webs of significance" that people both create and understand. The challenge is to see how they are created and understood-often in multiple and alternative ways.

We have a culture when a group of people living in a social, historical, and physical environment make sense of their experiences in a more or less unified manner. This means, for example, that they understand what other people say, they identify objects and events in similar ways, they find or do not find behavior appropriate in certain situations, they create objects, texts, and discourses that other members of the group find meaningful, and so forth. In all of these and innumerable other cases, we have meaning making in some form: not only in the sense of producing and understanding language but also in the sense of correctly identifying things, finding behavior acceptable or unacceptable, being able to follow a conversation, being able to generate meaningful objects and behavior for others in the group, and so forth. Meaning making is a cooperative enterprise (linguistic or otherwise) that always takes place in a large set of contexts (ranging from immediate to background) and

\footnotetext{
* I want to thank the Institute of Advanced Study and Van Mildert College, Durham University, for their generous support in the preparation of parts of this paper and the wonderful academic, social, and personal environment they provided for three months. My special thanks go to Andreas Musolff and David Cowling for the wonderful time we spent on studying metaphors.

Portions of this paper will also appear in Patrick Colm Hogan, editor, The Cambridge Encyclopedia of the Language Sciences, published by Cambridge University Press.
} 
that occurs with varying degrees of success. People who can successfully participate in this kind of meaning making can be said to belong to the same culture. Spectacular cases of unsuccessful participation in joint meaning making are called "culture shock."

This kind of meaning-based approach to culture can be found in Lakoff's work on American politics (Lakoff, 1996), Turner's (2001) investigations into the cognitive dimensions of social science, and Kövecses's $(2005,2006)$ study of metaphorical aspects of everyday culture. Palmer makes such a meaning-based approach the cornerstone of what he calls "cultural linguistics" and applies it to three central areas of anthropological linguistics: Boasian linguistics, ethnosemantics, and the ethnography of speaking (Palmer, 1996: 4-5).

What is required for meaning making? The main meaning making organ is the brain/mind. The BRAIN is the organ that performs the many cognitive operations that are needed for making sense of experience and that include categorization, figure-ground alignment, framing knowledge, metaphorical understanding, and several others. Cognitive linguists and cognitive scientists in general are in the business of describing these operations. Cognitive linguists believe that the same cognitive operations that human beings use for making sense of experience in general are used for making sense of language. On this view, language is structured by the same principles of operation as other modalities of the mind. However, these cognitive operations are not put to use in a universally similar manner, that is, there can be differences in which cognitive operations are used to make sense of some experience in preference to another and there can be differences in the degree to which particular operations are utilized in cultures. This leads to what is called "alternative construal" in cognitive linguistics (see Langacker, 1987). Moreover, the minds that evolve "on brains" in particular cultures are shaped by the various contexts (historical, physical, discourse, etc.) that in part constitute cultures (Kövecses, 2005). This leads to alternative conceptual systems.

Many of our most elementary experiences are universal. Being in a container, walking along a path, resisting some physical force, being in the dark, and so forth, are universal experiences that lead to image schemas of various kinds (Johnson, 1987; Lakoff, 1987). The resulting image schemas ("container," "source-path-goal," "force," etc.) provide meaning for much of our experience either directly or indirectly in the form of conceptual metaphors. Conceptual metaphors may also receive their motivation from certain correlations in experience, when, for instance, people see correlations between two events (such as adding to the content of a container and the level of the substance rising), leading to the metaphor MORE IS UP (see Lakoff and Johnson, 1980). 
When meaning making is based on such elementary human experiences, the result may be (near-)universal meaning (content) - though under a particular interpretation (construal), that is, conceived of "in a certain manner," to use Hoyt Alverson's phrase (Alverson, 1991: 97).

Language, on this view, consists of a set of linguistic signs, that is, pairings of form and meaning (which can range from simple morphemes to complex syntactic constructions). Learning a language means the learning of such linguistic signs. Thus, language can be regarded as a repository of meanings stored in the form of linguistic signs shared by members of a culture. This lends language a historical role in stabilizing and preserving a culture. This function becomes especially important in the case of endangered languages and it often explains why minorities insist on their language rights.

Members of a culture interact with each other for particular purposes. To achieve their goals, they produce particular discourses. Such discourses are assemblies of meanings that relate to particular subject matters. When such discourses provide a conceptual framework within which significant subject matters are discussed in a culture and when they function as latent norms of conduct, the discourses can be regarded as ideologies (see, e.g., CharterisBlack, 2004; Musolff, 2004; Goatly, 2007). Discourse in this sense is another source of making meaning in cultures. A large part of socialization involves the learning of how to make meaning in a culture.

In the remainder of this paper, I will explore metaphorical meaning making in two of its facets.

\section{METAPHORICAL MEANING MAKING}

In recent years, a large number of scholars have criticized the theory of conceptual metaphor for a variety of reasons (for example, Cameron, 2003, 2007; Clausner and Croft, 1997; Deignan, 1999; Dobrovolskij and Piirainen, 2005; Gevaert, 2001, 2005; Pragglejaz Group, 2007; Rakova, 2002; Ritchie, 2003; Semino, 2005; Steen, 1999; Stefanowitch, 2007; Zinken, 2007). Perhaps the most significant element of this criticism was the suggestion that conceptual metaphor theory ignores the study of metaphor in the contexts in which metaphorical expressions actually occur; namely, in real discourse. The claim is that the practitioners of "traditional" conceptual metaphor theory (i.e., Lakoff and Johnson and their ardent followers, like myself) set up certain, what they call conceptual metaphors and exemplify them with groups of (mostly) invented metaphors. In this way, traditional researchers in conceptual metaphor theory fail to notice some essential aspects of the study of metaphor 
and cannot account for phenomena that can only be accounted for if we investigate metaphors in real discourse.

I have responded to several aspects of this criticism in some previous publications (Kövecses, 2005; Kövecses, forthcoming, a, b, c) and I do not wish to repeat my response here, though it will be necessary to briefly bring some of that work into the present discussion. Instead, I will take the advice of the critics seriously, look at some pieces of real discourse where metaphors are used, and see how "traditional" conceptual metaphor theory can and should be modified and changed to accommodate at least some of the criticism.

\section{MetaPHORICAL COHERENCE IN DISCOURSE}

Most researchers who work on metaphor in real discourse would agree that a major function of the metaphors we find in discourse is to provide coherence (see, for example, Cameron, 2003; Charteris-Black, 2004; Chilton, 1996; Chilton and Ilyin, 1993; Deignan, 2005; Eubanks, 2000; Koller, 2004; Musolff, 2000, 2004, 2006; Ritchie, 2004a, b; Semino, in press/ 2008). The coherence metaphors can provide can be either intertextual or intratextual; that is, metaphors can either make several different texts coherent with each other or they can lend coherence to a single piece of discourse.

In some cases of intertextuality, intertextual coherence is achieved through inheriting and using a particular conceptual metaphor at different historical periods. One of the best examples of this is how several biblical metaphors have been recycled over the ages. Shortly after arriving in Durham, where I did the research for some of this work, I was given a bookmark in Durham cathedral with the following text on it:
Almighty God
Who called your servant Cuthbert
from keeping sheep to follow your son
and to be shepherd of your people.
Mercifully grant that we, following his
example and caring for those who are lost,
may bring them home to your fold.
Through your son.
Jesus Christ our Lord.
Amen.

In the prayer, the basic conceptual metaphor is the one in which the shepherd is Jesus, the lost sheep are the people who no longer follow God's teachings, 
the fold of the sheep is people's home with God, and for the shepherd to bring the sheep back to the fold is for Jesus to save the people. We can lay out these correspondences, or mappings, more explicitly as follows:

Source:

the shepherd

the lost sheep

the fold of the sheep

the shepherd bringing back the sheep $\rightarrow$
Target:

$\begin{array}{ll}\rightarrow & \text { Jesus } \\ \rightarrow & \text { the people who do not follow God } \\ \rightarrow & \text { the state of people following God }\end{array}$

This metaphor was reused later on when God called a simple man, called Cuthbert, to give up his job (which, significantly, was being a shepherd) and become a "shepherd of people." Here it is Cuthbert (not Jesus) who saves the lost people (a set of people different from the ones in Jesus' times). Finally, in the most recent recycling of the metaphor in the prayer said on St Cuthbert's day, $20^{\text {th }}$ March, 2007, the particular values of the metaphor change again. It is the priests who live today who try to bring people back to the fold - again, a set of people different from either those who lived in Jesus' or Cuthbert's times.

This type of intertextuality characterizes not only Christianity (and other religions) through time but many other domains within the same historical period. Thus a metaphor can provide coherence across a variety of discourses both historically and simultaneously.

In a similar fashion, the same conceptual metaphor can lend coherence to a single text. I call this "intratextual coherence." The metaphor that structures the discourse does not necessarily have to be a deeply entrenched conventional conceptual metaphor - it can be, what we can call, a metaphorical analogy of any kind. Consider the following three paragraphs, taken from the very beginning of a newspaper article:

Performance targets are identical to the puissance at the Horse of the Year Show. You know the one - the high-jump competition, where the poor, dumb horse is brought into the ring, asked to clear a massive red wall, and as a reward for its heroic effort is promptly brought back and asked to do it all over again, only higher.

I've never felt anything but admiration for those puissance horses which, not so dumb at all, swiftly realize that the game is a bogey. Why on earth should they bother straining heart, sinew and bone to leap higher than their own heads, only to be required to jump even higher? And then possibly higher still. 
Hard work and willingness, ponders the clever horse as he chomps in the stable that night, clearly bring only punishment. And so next time he's asked to canter up to the big red wall, he plants his front feet in the ground and shakes his head. And says, what do you take me for - an idiot? (Melanie Reid, The Times, Monday, February 4, 2008).

Here puissance horses are compared to people, riders to managers, the red walls as obstacles to the targets people have to achieve, having to jump over the obstacles to being subject to assessment, clearing the obstacles to achieving the targets, raising the obstacles to giving more difficult targets, the Horse Show to life, and so on and so forth. This elaborate metaphorical analogy provides a great deal of structure for the text. As a matter of fact, most of the structure of the text is given in terms of the metaphor up to this point in the article, with only the first two words ("performance targets") suggesting what the analogy is all about.

But then in the fourth paragraph the author lays out the correspondences for us, probably to make sure that we understand precisely what she has in mind:

Thus it is with work-related targets. Most of us will in the course of our careers be subject to performance assessments, where we are examined against the objectives we were set the previous year, then tasked with new ones.

From this point onward, the article uses predominantly literal language with some of the metaphorical language of the Horse Show interspersed in the text. At the end, however, the metaphor comes back in full force:

Oh, the bar may be set at what the politicians regard as a reasonable height. Aspirational enough to keep them all in power. From the perspective of the weary horse, however, we've reached the point where whipping doesn't work, but a carrot and a short rest just might.

Clearly, the metaphor is used here at the end of the article to make a point emphatically. This is a common rhetorical function that metaphors are assigned to perform in discourse. Thus, in addition to providing some of the internal coherence of the text, metaphors are often exploited for such and similar rhetorical functions (see, for example, Goatly, 1997).

What I would like to underscore here is that, in many cases, once introduced, conceptual metaphors (or metaphorical analogies) appear to have the effect of taking over what one says or thinks about a particular subject matter. We push the metaphor as far as it fits the target for our purposes. This way, on such 
occasions, conceptual metaphors or metaphorical analogies can predominate, or "rule," an entire discourse or a stretch of it.

\section{UNIVERSALITY AND VARIATION IN METAPHOR}

Native speakers of all languages use a large number of metaphors when they communicate about the world (Lakoff and Johnson, 1980). Such metaphorically used words and expressions may vary considerably across different languages. For example, the idea that English expresses with the words spending your time is expressed in Hungarian as filling your time. The "images" different languages and cultures employ code meanings can be extremely diverse. Given this diversity, it is natural to ask: Are there any universal metaphors at all, if by "universal" we mean those linguistic metaphors that occur in each and every language? Not only is this question difficult because it goes against our everyday experiences and intuitions as regards metaphorical language in diverse cultures, but also because it is extremely difficult to study, given that there are 4-6000 languages spoken around the world today.

However, if we go beyond looking at metaphorically used linguistic expressions in different languages, and, instead of linguistic metaphors, we look at conceptual metaphors, we begin to notice that many conceptual metaphors appear in a wide range of languages. For example, Hoyt Alverson (1994) found that the TIME IS SPACE conceptual metaphor can be found in such diverse languages and cultures as English, Mandarin Chinese, Hindi, and Sesotho. Many other researchers suggested that the same conceptual metaphor is present in a large number of additional languages. Several other conceptual metaphors appear in a large number of different languages. Kövecses (2000), based on evidence from a number of linguists who are native speakers of the respective languages, points out that English, Japanese, Chinese, Hungarian, Wolof, Zulu, Polish, and others, possess the metaphor AN ANGRY PERSON IS A PRESSURIZED CONTAINER to various degrees. Ning Yu's $(1995,1998)$ work indicates that the metaphor HAPPINESS IS UP is also present not only in English but also in Chinese. The system of metaphors called the Event Structure metaphor (Lakoff, 1993) includes submetaphors such as CAUSES ARE FORCES, STATES ARE CONTAINERS, PURPOSES ARE DESTINATIONS, ACTION IS MOTION, DIFFICULTIES ARE IMPEDIMENTS (то MOTION), and so forth. Remarkably, this set of submetaphors occurs, in addition to English, in such widely different languages and cultures as Chinese (Yu, 1998) and Hungarian (Kövecses, 2005). Eve Sweetser (1990) noticed that the KNOWING IS SEEING and the more general the MIND IS THE BODY metaphors can be found in many European languages and are probably good candidates for (near-)universal metaphors. As a final example, Lakoff and 
Johnson (1999) describe the metaphors used for one's inner life in English. It turns out that metaphors such as SELF CONTROL IS OBJECT POSSESSION, SUBJECT AND SELF ARE ADVERSARIES, THE SELF IS A CHILD, are shared by English, Japanese, and Hungarian. Given that one's inner life is a highly elusive phenomenon, and hence would seem to be heavily culture- and language-dependent, one would expect a great deal of significant cultural variation in such a metaphor. All in all, then, we have a number of cases that constitute near-universal or potentially universal conceptual metaphors, although not universal metaphors in the strong sense.

How is it possible that such conceptual metaphors exist in such diverse languages and cultures? After all, the languages belong to very different language families and represent very different cultures of the world. Several answers to this question lend themselves for consideration. First, we can suggest that by coincidence all these languages developed the same conceptual metaphors for happiness, time, purpose, etc. Second, we can consider the possibility that languages borrowed the metaphors from each other. Third, we can argue that there may be some universal basis for the same metaphors to develop in the diverse languages.

Let us take as an example the HAPPINESS IS UP conceptual metaphor, first discussed by Lakoff and Johnson (1980) in English. The conceptual metaphor can be seen in such linguistic expressions as feeling up, being on cloud nine, being high, and others. Yu $(1995,1998)$ noticed that the conceptual metaphor can also be found in Chinese. And evidence shows that it also exists in Hungarian. Below are some linguistic examples: (Yu used the grammatical abbreviations $\mathrm{PRT}=$ particle and $\mathrm{ASP}=$ aspect marker.)

Chinese:

\section{HAPPY IS UP}

Ta hen gao-xing. he very high-spirit

He is very high-spirited/happy.

Ta xing congcong de. he spirit rise-rise PRT

His spirits are rising and rising./He's pleased and excited.

Zhe-xia tiqi le wo-de xingzhi. this-moment raise ASP my mood This time it lifted my mood/interest. 
Hungarian:

\section{HAPPINESS IS UP}

Ez a film feldobott.

this the film up-threw-me

This film gave me a high.-This film made me happy.

Majd elszáll a boldogságtól.

almost away-flies-he/she the happiness-from

$\mathrm{He} / \mathrm{she}$ is on cloud nine.

English, Mandarin Chinese, and Hungarian (a Finno-Ugric language) belong to different language families, which developed independently for much of their history. It is also unlikely that the three languages had any significant impact on each other in their recent history. This is not to say that such an impact never shapes particular languages as regards their metaphors (e.g., the processes of globalization and the widespread use of the internet may "popularize" certain conceptual metaphors, such as TIME IS A COMMODITY), but only to suggest that the particular HAPPINESS IS UP metaphor does not exist in the three languages because, say, Hungarian borrowed it from Chinese and English from Hungarian.

So how did the same conceptual metaphor emerge then in these diverse languages? The best answer seems to be that there is some "universal bodily experience" that led to its emergence. Lakoff and Johnson argued early that English has the metaphor because when we are happy, we tend to be physically up, moving around, be active, jump up and down, smile (i.e., turn up the corners of the mouth), rather than down, inactive, and static, and so forth. These are undoubtedly universal experiences associated with happiness (or more precisely, joy), and they are likely to produce potentially universal (or near-universal) conceptual metaphors. The emergence of a potentially universal conceptual metaphor does not, of course, mean that the linguistic expressions themselves will be the same in different languages that possess a particular conceptual metaphor (Barcelona 2000; Gibbs, 2006; Maalej, 2004).

Kövecses $(1990,2000)$ proposed, furthermore, that the universal bodily experiences can be captured in the conceptual metonymies associated with particular concepts. Specifically, in the case of emotion concepts, such as happiness, anger, love, pride, and so forth, the metonymies correspond to various kinds of physiological, behavioral, and expressive reactions. These reactions provide us with a profile of the bodily basis of emotion concepts. Thus, the metonymies give us a sense of the embodied nature of concepts, 
and the embodiment of concepts may be overlapping, that is, (near-)universal, across different languages and language families. Such universal embodiment may lead to the emergence of shared conceptual metaphors.

Joseph Grady (1997a, b) developed the Lakoff-Johnson view further by proposing that we need to distinguish "complex metaphors" from "primary metaphors." His idea was that complex metaphors (e.g., THEORIES ARE BUILDINGS) are composed of primary metaphors (e.g., LOGICAL ORGANIZATION IS PHYSICAL STRUCTURE). The primary metaphors consist of correlations of a subjective experience with a physical experience. As a matter of fact, it turned out that many of the conceptual metaphors discussed in the cognitive linguistic literature are primary metaphors in this sense. For instance, HAPPY IS UP is best viewed as a primary metaphor, where being happy is a subjective experience and being physically up is a physical one that is repeatedly associated with it. Other primary metaphors include MORE IS UP, PURPOSES ARE DESTINATIONS, and INTIMACY IS CLOSENESS. On this view, it is the primary metaphors that are potentially universal.

Primary metaphors function at a fairly local and specific level of conceptualization, and hence in the brain. At the same time, we can also assume the existence of much more global metaphors. For example, animals are commonly viewed as humans and humans as animals; humans are commonly conceptualized as objects and objects as humans, and so on. A famous example of the "objects as humans" metaphor was described by Keith Basso (1967), who showed that in the language of the Western Apache cars are metaphorically viewed in terms of the human body. In addition, Bernd Heine and his colleagues work (Heine, Claudi, and Hünnemeyer, 1991, Heine, 1995, Heine and Kuteva, 2002) reveals other large-scale metaphorical processes people seem to employ (near-)universally; for example, spatial relations are commonly understood as parts of the human body (e.g., the head means up and the feet means down). These conceptual metaphors seem to be global designfeatures of the brain/mind of human beings.

It seems to be clear at this point that commonality in human experience is a major force shaping the metaphors we have. It is this force that gives us many of the metaphors that we can take to be near-universal or potentially universal. But commonality in human experience is not the only force that plays a role in the process of establishing and using metaphors. There are also counterveiling forces that work against universality in metaphor production. 


\section{Causes of Metaphor Variation}

Heine's work also shows that not even such global metaphors as SPATIAL RELATIONS ARE PARTS OF THE BODY are universal in an absolute sense. There are languages in which spatial relations are conceptualized not as the human but as the animal body. He points out that such languages function in societies where animal husbandry is a main form of subsistence. This leads us to the question: What causes our metaphors to vary as they do? It is convenient to set up two large groups of causes: differential experience and differential cognitive preferences. Differential experience involves differences in socialcultural context, in social and personal history, and in what we can term social and personal concern or interest (see Kövecses, 2005).

One example of how the social-cultural context can shape conceptual metaphors is provided by Geeraerts and Grondelaers (1995). They note that in the Euro-American tradition it is the classical-medieval notion of the "four humors" from which the Euro-American conceptualization of anger (as well as that of emotion in general) derived. The humoral view maintains that the four fluids (phlegm, black bile, yellow bile, and blood) and the temperatures associated with them regulate the vital processes of the human body. They were also believed to determine personality types (such as sanguine, melancholy, etc.) and account for a number of medical problems. The humoral view exerted a major impact on the emergence of the European conception of anger as a hot fluid in a pressurized container. By contrast, King (1989) and Yu (1995 and 1998) suggest that the Chinese concept of "nu" (corresponding to anger) is bound up with the notion of "qi," that is, the energy that flows through the body. "Qi" in turn is embedded in not only the psychological (i.e., emotional) but also the philosophical and medical discourse of Chinese culture and civilization. When "qi" rises in the body, there is anger ("nu"). Without the concept of "qi," it would be difficult to imagine the view of anger in Chinese culture. Thus emotion concepts, such as "anger" in English, "düh" in Hungarian (the two representing European culture), and "nu" in Chinese, are in part explained in the respective cultures by the culture-specific concepts of the four humors and "qi," respectively. It appears that the culture-specific key concepts that operate in particular cultures account for many of the specific-level differences among the various anger-related concepts and the PRESSURIZED CONTAINER metaphor.

An example of how differences in human concern can create new metaphors, consider some well known conceptual metaphors for sadness: SADNESS IS DOWN, SADNESS IS A BURDEN, and SADNESS IS DARK. The counterpart of sadness is depression in a clinical context. Linda McMullen and John Conway 
(2002) studied the metaphors that people with episodes of depression use and, with one exception, found the same conceptual metaphors for depression that "non-depressed" people use for sadness. They identified the unique metaphor as DEPRESSION IS A CAPTOR. Why don't "merely" sad people talk about sadness as being a "captor"? Most people do not normally talk about being trapped by, wanting to be free of, or wanting to break out of sadness, although these are ways of talking and thinking about depression in a clinical context. It makes sense to suggest that people with depression use this language and way of thinking about their situation because it faithfully captures what they experience and feel. Their deep concern is with their unique experiences and feelings that set them apart from people who do not have them. It is this concern that gives them the CAPTOR metaphor for depression.

People can employ a variety of different cognitive operations in their effort to make sense of experience. For example, what I call 'experiential focus' can have an impact on the specific details of the conceptual metaphors used and what is conceptualized metaphorically in one culture can predominantly be conceptualized by means of metonymy in another (Kövecses, 2005). The universal bodily basis on which universal metaphors could be built may not be utilized in the same way or to the same extent in different languages. What experiential focus means is that different peoples may be attuned to different aspects of their bodily functioning in relation to a metaphorical target domain, or that they can ignore or downplay certain aspects of their bodily functioning with respect to the metaphorical conceptualization of a target domain. A case in point is the conceptualization of anger in English and Chinese. As studies of the physiology of anger across several unrelated cultures show, increase in skin temperature and blood pressure are universal physiological correlates of anger (Levenson, R. W., P. Ekman, K. Heider, and W. V. Friesen, 1992). This accounts for the ANGER IS HEAT metaphor in English and in many other languages. However, King's and Yu's work mentioned above suggest that the conceptualization of anger in terms of heat is much less prevalent in Chinese than it is in English. In Chinese, the major metaphors of anger seem to be based on pressure-not heat. This indicates that speakers of Chinese have relied on a different aspect of their physiology in the metaphorical conceptualization of anger than speakers of English. The major point is that in many cases the universality of experiential basis does not necessarily lead to universally equivalent conceptualization-at least not at the specific level of hot fluids.

Are there any differences in the way the cognitive processes of metaphor versus metonymy are used in different languages and cultures? Jonathan Charteris-Black (2003) examined in great detail how and for what purpose three concepts-mouth, tongue, and lip-are figuratively utilized in English and 
Malay. He found similarities in metaphorical conceptualization. For example, in both languages, the same underlying conceptual metaphor (e.g., MANNER IS TASTE) accounts for expressions like honey-tongued and lidah manis ("tongue sweet') and in both languages such expressions are used for the discourse function of evaluating (especially negatively) what a person says. However, he also found that the figurative expressions involving the three concepts tended to be metonymic in English and metaphoric in Malay. In English, more than half of the expressions were metonyms, while in Malay the vast majority of them showed evidence of metaphor (often in combination with metonymy). For example, while metonymic expressions like tight-lipped abound in English, such expressions are much less frequent in Malay. It seems that, at least in the domain of speech organs, the employment of these concepts by means of figurative processes is partially culture-specific.

In sum, metaphorical linguistic expressions may vary widely crossculturally but many conceptual metaphors appear to be potentially universal or near-universal. This happens because people across the world share certain bodily experiences. However, even such potentially universal metaphors may display variation in their specific details because people do not use their cognitive capacities in the same way from culture to culture. Moreover, shared conceptual metaphors may vary crossculturally in the frequency of their use. Finally, many conceptual metaphors are unique to particular (sub)cultures or sets of cultures because of differences in such factors as social-cultural context, history, or human concern that characterize these cultures.

\section{Conclusions}

Culture and language are connected in many ways and the interconnections can be studied from a variety of different perspectives. Following Clifford Geertz, I tried to develop a view of the relationship that is based on how we make sense of our experiences-linguistic or otherwise. Recent cognitive science and cognitive linguistics provide us with new ideas and methodological tools with which we can approach the issue of meaning-making in cultures both in its universal aspects and in its infinite cross-cultural variety. If the cognitive linguistic view of metaphor is on the right track (as I believe it is), a large part of our making sense of the world is based on metaphorical ways of speaking and thinking. With the help of our metaphorical meaning-making apparatus, we make a large portion of our discourses coherent. Some of the metaphors we use for this purpose are universal and some of them are culturespecific. We have seen the most important causes that make metaphors either universal or culture-specific (or a combination of the two). In metaphorical 
conceptualization, we seem to be under constant pressure to accommodate both the force of the body and context. Our metaphorical meaning making is the function of these two forces.

\section{REFERENCES}

Alverson, H. (1991). "Metaphor and experience: Looking over the notion of image schema." In: J. Fernández (ed.). Beyond Metaphor: The Theory of Tropes in Anthropology, 94-117. Stanford: Stanford University Press.

Alverson, H. (1994). Semantics and Experience: Universal Metaphors of time in English, Mandarin, Hindi, and Sesotho. Baltimore: Johns Hopkins University Press.

Barcelona Sánchez, A. (2000). "On the plausibility of claiming a metonymic motivation for conceptual metaphor". In: A. Barcelona Sánchez (ed.). Metaphor and Metonymy at the Crossroads, 31-58. Berlin: Mouton de Gruyter.

Basso, K. H. (1967). "Semantic Aspects of Linguistic Acculturation". American Anthropologist New Series 69(5): 471-477

Cameron, L. (2003). Metaphor in Educational Discourse. London: Continuum.

Cameron, L. (2007). "Patterns of metaphor use in reconciliation talk". Discourse and Society 18, 197-222.

Charteris-Black, J. (2003). "Speaking with forked tongue: A comparative study of metaphor and metonymy in English and Malay phraseology". Metaphor and Symbol 18(4): 289-310.

Charteris-Black, J. (2004). Corpus Approaches to Critical Metaphor Analysis. Basingstoke/New York: Palgrave/MacMillan.

Chilton, P. \& M. Ilyin (1993). "Metaphor in political discourse. The case of the "Common European House"'. Discourse and Society 4(1): 7-31.

Chilton, P. (1996). Security Metaphors: Cold War Discourse from Containment to Common European Home. Frankfurt: Peter Lang.

Clausner, T. \& W. Croft (1997). "Productivity and schematicity in metaphors". Cognitive Science 21(3): 247-282.

Deignan, A. (1999). "Corpus-based research into metaphor". In: L. Cameron \& G. Low (eds.). Researching and Applying Metaphor, 177-199. Cambridge: Cambridge University Press.

Deignan, A. (2005). Metaphor and Corpus Linguistics. Amsterdam: John Benjamins.

Dobrovolskij, D. \& E. Piirainen (2005). Figurative Language. Cross-cultural and Cross-linguistic Perspectives. Amsterdam: Elsevier. 
Eubanks, P. (2000). A War of Words in the Discourse of Trade. The Rhetorical Constitution of Metaphor. Southern Illinois University Press.

Geeraerts, D. \& S. Grondelaers, S. (1995). "Looking back at anger: cultural traditions and metaphorical patterns.” In: J. Taylor \& R. MacLaury (eds.). Language and the cognitive construal of the world, 153-179. Berlin: Gruyter.

Geertz, C. (1973). The Interpretation of Cultures. New York: Basic Books.

Gevaert, C. (2001). “Anger in old and middle English: a 'hot' topic?". Belgian Essays on Language and Literature: 89-101.

Gevaert, C. (2005). "The anger is heat question: detecting cultural influence on the conceptualization of anger through diachronic corpus analysis". In: N. Delbacque, J. Van der Auwera \& G. Geeraerts (eds.). Perspectives on Variation: Sociolinguistic, Historical, Comparative, 195-208. Berlin: Mouton de Gruyter.

Gibbs, R. W. (2006). Embodiment and Cognitive Science. New York: Cambridge University Press.

Goatly, A. (1997). The Language of Metaphors. London: Routledge.

Goatly, A. (2007). Washing the Brain. Metaphor and Hidden Ideology. Amsterdam: John Benjamins.

Grady, J. (1997a). Foundations of Meaning: Primary Metaphors and Primary Scenes. Ph.D. diss. Department of Linguistics, University of California at Berkeley.

Grady, J. (1997b). “THEORIES ARE BUILDING revisited”. Cognitive Linguistics 8: 267-290.

Heine, B. \& T. Kuteva (2002). World Lexicon of Grammaticalization. Cambridge: Cambridge University Press.

Heine, B., U. Claudi \& F. Hünnemeyer (1991). Grammaticalization: A Conceptual Framework. Chicago: University of Chicago Press.

Heine, B. (1995). Conceptual grammaticalization and prediction. In: J. Taylor $\&$ R. MacLaury (eds.). Language and the Cognitive Construal of the World. 119-135. Berlin: Mouton de Gruyter.

Johnson, M. (1987). The Body in the Mind. Chicago: The University of Chicago Press.

King, B. (1989). The conceptual structure of emotional experience in Chinese. $\mathrm{Ph} . \mathrm{D}$. dissertation. Ohio State University.

Koller, V. (2004/2008). Metaphor and Gender in Business Media Discourse: a Critical Cognitive Study. Basingstoke/New York: Palgrave.

Kövecses, Z. (1990). Emotion Concepts. Berlin/New York: Springer/Verlag.

Kövecses, Z. (2000). Metaphor and Emotion. New York/Cambridge: Cambridge University Press. 
Kövecses, Z. (2002). Metaphor. A Practical Introduction. New York: Oxford University Press.

Kövecses, Z. (2005). Metaphor in Culture. Universality and Variation. Cambridge and New York: Cambridge University Press.

Kövecses, Z. (2006). Language, Mind, and Culture. A Practical Introduction. Oxford and New York: Oxford University Press.

Kövecses, Z. (Forthcoming, a). "Conceptual metaphor theory: some criticisms and some alternative proposals". Annual Review of Cognitive Linguistics.

Kövecses, Z. (Forthcoming, b). "Methodological issues in conceptual metaphor theory". In: H.-J. Schmid \& S. Handl (eds.). Windows to the Mind. Metaphor, Metonymy, and Conceptual Blending. Berlin: Mouton de Gruyter.

Kövecses, Z. (Forthcoming, c). "Metaphor, culture, and discourse: the pressure of coherence". In: A. Musolff \& H.-J. Zinken (eds.). Metaphor and Discourses. Palgrave Macmillan.

Lakoff, G. \& M. Johnson (1980). Metaphors We Live By. Chicago: The University of Chicago Press.

Lakoff, G. \& M. Johnson (1999). Philosophy in the Flesh. The Embodied Mind and its Challenge to Western Thought. New York: Basic Books.

Lakoff, G. (1987). Women, Fire, and Dangerous Thing. Chicago: The University of Chicago Press.

Lakoff, G. (1993). "The contemporary theory of metaphor". In: A. Ortony (ed.). Metaphor and Thought, 202-251. Cambridge: Cambridge University Press.

Lakoff, G. (1996). Moral Politics. How Liberals and Conservatives Think. Chicago: The University of Chicago Press.

Langacker, R. (1987). Foundations of Cognitive Grammar. Theoretical Prerequisites. Vol. 1. Stanford: Stanford University Press.

Levenson, R. W., P. Ekman, K. Heider \& W. V. Friesen (1992). "Emotion and autonomic nervous system activity in the Minangkabau of West Sumatra". Journal of Personality and Social Psychology 62: 972-988.

Maalej, Z. (2004). "Figurative language in anger expressions in Tunisian Arabic: An extended view of embodiment". Metaphor and Symbol 19(1): 51-75.

McMullen, L. \& J. Conway (2002). "Conventional metaphors for depression". In: S. Fussell (ed.). Verbal communication of emotion: interdisciplinary perspectives, 167-181. Mahwah: Lawrence Erlbaum.

Musolff, A. (2000). "Political Imagery of Europe: a house without exit doors?". Journal of Multilingual and Multicultural Development 21(3): 216-229.

Musolff, A. (2004). Metaphor and Political Discourse. Analogical Reasoning in Debates about Europe. Basingstoke: Palgrave Macmillan. 
Musolff, A. (2006). "Metaphor scenarios in public discourse". Metaphor and Symbol 21(1): 23-38.

Palmer, G. (1996). Toward a Theory of Cultural Linguistics. Austin: Texas University Press.

Pragglejaz Group (2007). "MIP: A method for identifying metaphorically used words in discourse". Metaphor and Symbol 22(1): 1-39.

Rakova, M. (2002). "The philosophy of embodied realism: A high price to pay?”. Cognitive Linguistics 13(3): 215-244.

Ritchie, D. (2003). "ARGUMENT IS WAR - Or is it a game of chess? Multiple meanings in the analysis of imiplicit metaphors". Metaphor and Symbol 18(2): 125-146.

Ritchie, D. (2004a). "Metaphors in Conversational Context: Toward a Connectivity Theory of Metaphor Interpretation". Metaphor and Symbol 19: 265-287.

Ritchie, D. (2004b). "Common Ground in Metaphor Theory: Continuing the Conversation". Metaphor and Symbol 19: 233-244.

Semino, E. (2005). "The metaphorical construction of complex domains: The case of speech activity in English". Metaphor and Symbol 20-21:35-70.

Semino, E. (In press/2008). Metaphor in Discourse. Cambridge: Cambridge University Press.

Steen, G. (1999). "From linguistic to conceptual metaphor in five steps". In: R. Gibbs \& G. Steen (eds.). Metaphor in Cognitive Linguistics, 57-77. Amsterdam: John Benjamins.

Stefanowitch, A. (2007). "Words and their metaphors". In: A. Stefanowitch \& S. Th. Gries (eds.). Corpus-based Approaches to Metaphor and Metonymy, 64-105. Berlin: Mouton de Gruyter.

Sweetser, E. (1990). From Etymology to Pragmatics. Cambridge/New York: Cambridge University Press.

Turner, M. (2001). Cognitive Dimensions of Social Science. Oxford and New York: Oxford University Press.

Yu, N. (1995). "Metaphorical expressions of anger and happiness in English and Chinese". Metaphor and Symbolic Activity 10: 59-92.

Yu, N. (1998). The contemporary theory of metaphor in Chinese: A perspective from Chinese. Amsterdam: John Benjamins.

Zinken, J. (2007). "Discourse metaphors: the link between figurative language and habitual analogies"". Cognitive Linguistics 18(3): 445-466. 